\title{
AS PERGUNTAS NA ORGANIZAÇÃO DAS ENTREVISTAS
}

\author{
Leonor Lopes Fávero * \\ Zilda C.O.Aquino* *
}

RESUMO: Este arligo discute o papel das perguntas como elementos organizadores dos lextos de entrevistas, não só em relação ao lurno, mas também no que se refere ao tópico discursivo, dinamizando a interação e reorganizando o contexto.

PALAVRAS-CILAVE: entrevistas, par dialógico, contexto e relevância, tópico discursivo.

\section{AS ENTREVISTAS}

1 s pesquisas realizadas com textos falados têm apontado para tre os quais a dialogicidade, a interação centrada, o plancjamento local. Há muito o que se dizer dos textos falados, especialmente quando se trata dos textos de entrevistas. Correspondem a uma atividade em que não só jornalistas ou pessoas ligadas diretamente à área da comunicação estão engajadas, mas também todos nós, de uma forma ou de outra participamos, como entrevistadores ou entrevistados, conforme observa Carret (1981). É comum tomarem-se os textos de entrevistas como tipicamente assimétricos em que um dos participantes tem o direito de iniciar, orientar, dirigir e concluir a interação e exercer pressão sobre o(s) outro(s) participante(s) (Marcuschi, 1986:16). Mas, em verdade, voltar a atenção para textos que se constroem sob a forma de entrevistas significa deparar com uma escala de possibilidades que abrange do menor ao maior grau de dialogicidade.

* Universidade de São Paulo - USP.

* Faculdades Oswaldo Cruz. 
FÁVERO, Lconor Lopes., el alii. As perguntas na organização das entrevistas.

Dependendo de quem seja o entrevistador ou do papel que the destinem, a entrevista pode constituir apenas uma técnica em que se obtêm respostas já esperadas a partir da organização de um simples questionário e, neste caso, um pré-texto já estaria construído anteriormente ao encontro e seria preenchido tão somente com as respostas do entrevistado. Tomando-se a interação em termos de possibilidade de enquadramento $\mathrm{cm}$ uma escala, poder-se-ia dizer que, nesses textos, observa-se um direcionamento para o menor grau nessa escala de interação. Por outro lado, é possível ocorrer um grau elevado de dialogicidade $\mathrm{em}$ que o entrevistador deixa o texto fluir e transcorrer de tal forma que este não se identifique com um mero monólogo.

Fatos como os indicados são facilmente observáveis e um ouvinte ou um telespectador não precisa de grandes conhecimentos lingüísticos para detectá-lo. Assim é que muitas pessoas comentam a respeito deste ou daquele entrevistador que, em casos extremos, mal deixa o entrevistado completar seu enunciado, cortando ou sobrepondo-se a sua fala, detectandose um "dirigismo" na tarefa executada pelo entrevistador; que imprime um ritmo em sua pauta, preestabelecendo as respostas de modo a obter tais resultados do interlocutor que é conduzido.

Segundo Medina (1990:7), os meios de divulgação atuais acentuam a incomunicação. Entretanto, é possível, embora não seja usual, que os interlocutores saiam modificados após terem participado de uma verdadeira atividade interacional, no sentido de que há possibilidade de ser atingido um alto grau na escala da interação, da construção espontânea. "Em certos casos felizes, a entrevista torna-se diálogo; este é uma busca em comum em que entrevistador e entrevistado colaboram no sentido de trazer à tona uma verdade que pode dizer respeito à pessoa do entrevistado ou a um problema."

Embora se possa analisar, por exemplo, ontologicamente o jogo de aparências que, muitas vezes, se instaura, cabe-nos descrever e analisar o modo como esses participantes da atividade conversacional constroem seus 
textos, claboram seus enunciados de forma a atingir os objetivos a que se propuseram. Entendemos que a organização do texto de entrevistas não pode prescindir da presença das Perguntas em sua constituição. Nesse sentido, nosso enfoque consiste $\mathrm{em}$ atribuir às perguntas um papel privilegiado, considerando-as elementos-chave que, associados ao contexto e aos objetivos conversacionais, acabam por revelar uma organização textual peculiar, determinando, inclusive, o desenvolvimento da atividade interacional que se pode mostrar de modo diferenciado. Interessa, então, observar como ás perguntas se insertam no texto que vão criando e a interação que promovem.

Apontaremos para o fato de que as perguntas se constituem em estratégias cujos efeitos são cumulativos, isto é, o entrevistador pode formular um pedido de informação, de confirmação ou esclarecimento, ao mesmo tempo cm que pode utilizá-la para introduzir, mudar, redirecionar o tópico. Outra possibilidade corresponde, por exemplo, à utilização da pergunta como elemento de manutenção do tópico, aproveitando para mexer com a face do entrevistado.

Aos estudar as perguntas, Caulmyn (1991:321) salienta que "la question se définit en discours par le couple qu'clle forme avec sa réponse" em que se observam dois turnos não só sucessivos, mas também complementares.

Em trabalho anterior (Fávero, Andrade e Aquino, 1996), indicamos que o par Pergunta-Resposta (P/R) é um dos fatores que concorrem para o estabelecimento da coerência conversacional e que não há necessariamente uma única resposta $(R)$ possível a uma dada $(P)$, isto ć, as possibilidades de precnchimento são várias. Em relação ao que determina esse preenchimento, pode-se dizer que ele está associado, entre outros fatores, ao contexto de ocorrência da P. A esse respeito, Caulmyn (op.cit.) já salientara que uma pergunta não pode ser analisada fora de seu contexto de ocorrência e que, na ausência de marcas formais indiscutíveis, só ele permite inferir se houve uma pergunta.

Embora se indique que, algumas vezes, um participante formula uma pergunta de modo que scu interlocutor a interpreta da mancira que 
FÁVERO, Lconor Lopes., el alii. As perguntas na organização das entrevistas.

quer, ou seja, sem se importar com o tipo de resposta que será fornecida, a quase totalidade das perguntas é formulada $\mathrm{cm}$ decorrência do contexto discursivo anterior, fato que permite indicar a importância do contexto precedente da pergunta o qual acaba por emoldurá-la.

I lá segmentos do texto de entrevistas em que as perguntas parecem servir como invólucros para camuflar uma asserção e o entrevistado toma uma formulação desse tipo realmente como asserção c não como um cnunciado que demanda, por exemplo, um preenchimento de sim ou não. A esse respeito destacam-se os estudos de Kerbrat-Orecchioni (1991) que atribuem à pergunta um papel intermediário entre $\mathrm{a}$ ordem $\mathrm{e}$ a asserção. A autora considera existir um continuum entre pergunta $\mathrm{c}$ asserção.

Nas entrevistas, as perguntas colocam-se como parte de um jogo em que os participantes precisam detectar as regras para poderem se sair bem, já que muitas vezes clas se constituem em estratégia do locutor para revelar a face negativa do interlocutor.

Consideramos que uma análise não se deva reportar apenas ao modo como o texto se apresenta organizado lingüisticamente, mas observar como o lingüístico está relacionado ao mesmo tempo que depende do contexto. Nesse sentido, é preciso considerar a importância que assumem a relevância c o contexto na direção da formulação textual, tornando-se imprescindível que sejam esses elementos tomados em consideração quando se analisam as perguntas no texto de entrevistas.

A concepção de contexto não se tem apresentada como única e a clucidação do que o constitui comporta questões que não se esgotam entre os estudiosos da área. I lá unanimidade quanto a considerar as formulações lingüísticas e o contexto como fenômenos interdependentes, não se podendo, então, dispensar-lhe um tratamento autônomo, senão relacionado à linguagem em uso, atentando-se para sua concernência. Conforme já indicara Bakhtin (1973:75):

"Verbal communication can never be understood and explained outside of connection with a concrete situation... Language 
Revisla da ANPOLL, n“ 4, p. 121-135, jan./jun. 1998

acquires life and historically evolves... in concrete verbal communication, and not in the abstract system of language forms, nor in the individual psyche of speakers".

Também os estudiosos Sacks, Schegloff e Jefferson (1974) afirmam que um recurso de que os participantes se utilizam para construir a fala é o posicionamento dentro de uma outra ocorrência o que constitui um aspecto básico do contexto.

Merecem, ainda, destaque os trabalhos de Iindstrom (1992:104), para quem "o contexto pode ser definido como o conjunto de procedimentos e condições discursivas que organizam as qualificações e oportunidades que os falantes têm de formular os enunciados e que estabelece as condições em relação ao modo como esses enunciados podem ser interpretados.

Ao enfatizarem a importância do contexto, Coodwin c Coodwin (1992) salientam o fato de ser a construção da significação bastante complexa e dela participarem ações realizadas, comportamentos e inferências cuja investigação permite visualizar que se trata de um processo colaborativo em que os participantes estão bastante envolvidos.

Estes autores destacam, dentre as várias possibilidades de contexto, um tipo especial - o contexto relevante - modelado pelas atividades específicas que estão sendo realizadas no momento. É preciso considerar, ainda, a capacidade do ser humano em remodelar dinamicamente o contexto, proporcionando uma organização diferenciada para sua ação dentro da interação e, assim, o contexto relevante de um enunciado pode ser a própria situação (Coffman,1981).

Podemos, então, afirmar que os participantes não estão apenas envolvidos num determinado contexto, mas, como participantes ativos, são responsáveis pelo processo de construção desse contexto a quem cabe a tarefa de atualizar o conteúdo do cnunciado. Sua característica de biderecionalidade permite, ao mesmo tempo, influir na formulação dos enunciados, reportando ao contexto anterior e projetando o contexto seguinte. Podemos, desse modo, entender que os participantes, por meio de 
FÁVERO, Leonor I sopes., el alii. As perguntas na organização das entrevistas.

suas formulações, constituem a atividade discursiva e projetam no contexto imediato o contexto subseqüente e a pergunta desempenha o importante papel de elemento propulsor que encaminha a compreensão desse contexto, criando um campo de relevância.

É preciso lembrar a importância que o tópico assume na organização do texto conversacional. Os interlocutores formulam suas perguntas tendo $\mathrm{em}$ vista o tópico $\mathrm{em}$ andamento ${ }^{1}$ e estas são inseridas de modo estratégico seja introduzindo um tópico, dando-lhe continuidade por não ter sido suficientemente explorado, redirecionando-o, mudando-o numa manobra considerada relevante por um dos interlocutores etc.

Sabemos que não há uma organização imposta e abrangente a todos os tipos de contexto. Assim, cada entrevista pode ser considerada única, particular. Embora conheçamos a linha de conduta do programa sob análise - Roda Viva -, é preciso lembrar que somente o mediador costuma ser o mesmo; os outros participantes variam de acordo com o entrevistado, de tal modo que, ao convidarem um político (como Fleury), os entrevistadores são, em sua maioria, jornalistas que assinam colunas a respeito de política e que trabalham para jornais renomados do país (entre eles estão presentes Rui Xavier - coordenador de política de O Estado de S. Paulo -, Milton Abrúcio - repórter político de Jornal do Brasil -, José Luiz Longo - repórter especial de política do jornal O Globo).

Em decorrência do que até aqui expusemos, temos que, para efetuar uma análise, é preciso levar em conta seu tipo específico, o que neste contexto está em relevância, o tópico que está sendo desenvolvido, as propriedades dos membros envolvidos, a partir daí é que se poderão analisar as propriedades específicas em termos de ações, interações dos falantes, atentos as suas especificidades no que concerne a seus conhecimentos, suas crenças, seus valores, seus desejos, seus sentimentos, suas emoções etc. (Aquino,1997:68)

1 As relaçóes entre pergunta e tópico discursivo foram estudadas no trabalho "Perguntas e respostas como mecanismos de coesão e coerência", realizado em conjunto com Maria I úcia C.V.O.Andrade, publicado em A.T.Castilho e M. Basílio (1996). 
Revista da ANPOLLL, n 4, p. 121-135, jan./jun. 1998

\section{A ENTREVISTA NO PROJETO NURC/SP}

Nas entrevistas do NURC/SP (tipo DID), as formulações do Documentador são representadas quase sempre por perguntas, pois a preocupação é deixar o entrevistado falar, não importando o que ele possa dizer, mas de que mancira o dirá. Não se pode perder de vista o objetivo conversacional que é lingüístico, não havendo preocupação com o conteúdo, dada a proposta do Projeto. Conseqüentemente, observa-se um planejamento específico por parte do Documentador, marcado por uma assimetria acentuada nas relações entre os participantes, resultando num texto com menor grau de dialogicidade.

Nesses inquéritos, as perguntas têm um papel específico, não buscam informação, mas somente querem fazer o entrevistado falar; colocam-se, assim, como elementos criadores de situação e, muitas vezes, entrevistador e entrevistado acabam por rir-se, quando a pergunta cria um contexto de irrelevância, debruçando-se sobre o óbvio, como se observa no segmento:

Doc. quando você tem algum problema de vista você recorre a quem?

Inf. ao oculista e posteriormente a uma ótica ((risos))

(Inquérito 254, lin. 211-214)

ou quando a resposta mostra ao Documentador que este já havia tratado daquele tópico, apontando para uma questão de irrelevância:

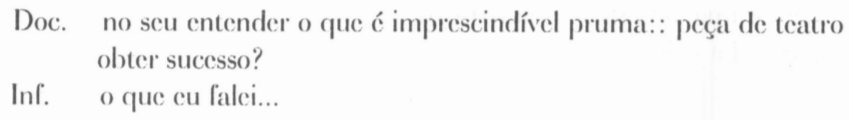

(Inquérito 161, lin.322-24)

O Documentador já havia formulado essa pergunta às linhas 234-35, repete-a, parafraseando-a, ao que o interlocutor, percebendo, avisa "o que cu falei". A mesma pergunta será parafraseada às linhas. 488-89 c o informante torna a avisá-lo a respeito da irrelevância com a formulação "o que eu disse". 
FÁVERO, Lconor Lopes., el alii. As pergunlas na organização das entrevistas.

A participação do entrevistador, nos inquéritos 18, 137, 208, 251, do NURC, quando não está lançando mão de perguntas, óbvias, como as que acabamos de citar, ou organizadas de forma genérica, resume-se, muitas vezes, à emissão de sinais de assentimento, do ouvinte, como "uhn uhn" ou "certo", ou a risos.

Porém, encontramos registro de ocorrência em que a interação é mais "natural" no Inquérito 18 , às linhas 437-38:

Doc. que tipo de arroz o senhor consome/ ((riu)) também não sabe é solteiro né ((risos))

observa-se, neste caso, que o próprio Documentador salienta a irrelevância da questão formulada c ri.

No inquérito161, as perguntas não são tão curtas, nem tão óbvias e os turnos do Documentador indicam sinais de que o assunto da entrevista já tinha sido tratado anteriormente, como ocorre à linha 150:

Doc. como falei... como tinha falado pra vocês quando nós estávamos conversando antes

Dentre os inquéritos, o de número 234 (linhas 154-56) destaca-se por apresentar um Documentador que interage mais, fazendo inclusive obscrvações quanto à expressão facial da informante:

Doc. não gosta de drama?

Inf. não drama já basta a vida ((risos))

Doc. a carinha dela

\section{A ENTREVISTA NA TV}

Considerando-se o material sob análise, é possível afirmar que os resultados obtidos podem ser diferenciados quando se observam entrevis- 
tas apresentadas pela televisão; nestas, em decorrência de serem os objetivos conversacionais diferentes daqueles do Projeto NURC, as perguntas são utilizadas de forma estratégica, dinamizam a interação verbal, ajustam a participação dos interlocutores, reorganizam o contexto e permitem ao entrevistador explorar a organização seqüencial e, automaticamente, a organização contextual como recurso criativo para a organização das atividades em que entrevistador e entrevistado estejam envolvidos.

Além disso, temos sempre presentes questões como a do envolvimento do auditório (terceira parte) e a da polidez, especialmente quando são convidadas personalidades do mundo político, enfoque específico deste trabalho.

Tomando-se por exemplo as transcrições do programa Roda Viva, apresentado pela TV Cultura de São Paulo, em 26/12/94, destacamos um segmento em que um dos entrevistadores - Rui Xavier, identificado como L 9 - apresenta ao Covernador I Luiz Antonio Flcury Filho (L 2) a posição do futuro Governador Mário Covas durante uma entrevista fornecida à mesma emissora em que ocorre uma avaliação a respeito do governo Fleury (lin. 760 e ss.):

L9 (...) o governador eleito Mário Covas... ele falou MUlto MAL, de São Paulo... quer dizer... da administração da sua administração (...) ele deu uma situação... um um uma visão muito caótica do que ele vai receber aliás ele usou esse termo caótico... é esse mesmo o quadro?

A pergunta de Rui Xavier cria uma situação de irrelevância em que não só se formula um pedido de informação, mas ainda se constrói um lugar específico na interação em que uma posição será publicamente estabelecida. Traços da fala do entrevistador permitem observar ênfase em aspectos negativos quanto à administração de Fleury (MUIto MAL) e a qualificação como caótica, observando-se uma seleção que passa impressões específicas. 
FÁVERO, Lconor Lopes., el alii. As perguntas na organização das entrevistas.

Ao que Fleury responde sem apresentar argumentos (lin.775):

L2 não não é

Mais adiante (lin.851 e ss.), L9 torna a claborar uma pergunta que retoma esse tópico e que, ao mesmo tempo, mostra a preocupação do entrevistador em relação à terceira parte, convidando Fleury a argumentar um pouco mais em scu favor, reforçando sua posição. Entretanto, o governador acaba por organizar seu discurso, apresentando uma resposta em que não se detectam argumentos fortes que possibilitariam convencer entrevistador e, certamente, terceira parte:

L9 agora governador... ( ) uma coisinha

$\mathrm{L} 2$ pois não

L9 como é que Fica o cidadão de São Paulo... que vive aqui em São Paulo enfim o cidadão paulista

I.2 ahn ahn

L9 éh:: ele assiste na segunda-feira... se ele assiste os dois programas ele vai fundir a Cuca... porque vem o governador eleito diz que.. tamos vivendo no Caos... o governador que tá saindo diz que tá tudo bem

I.2 e tá

1,9 como é que a gente ( )

l,2 não não não tá... o o o veja bem eu diria que tá tudo bem... agora... essas informaçöes... por isso me preocupou é:: é:: simples... vamos lá vocês são jornalistas... e tão convidados amanhã... a eu mostro... dá pra tocar... botar a mão... é turbina... tá lá...

Depois de transcorridos alguns turnos, L 49 retoma a questão da administração de Fleury e questiona (lin. 1041):

L9 o senhor sabe que o:: que o:: que o governador ( ) este governador cleito... deu nota ao seu governo né?... o senhor viu aquela parte?

1.2 กล̃o กล̃o vi

L.3 disse que o senhor ficou de recuperação ((risos dos entrevistadores))

L9 ((sorrindo)) o senhor daria que nota ao governo Fleury?

L2 ahn eu... eu acho que fui aprovado 
Resposta na qual os entrevistadores parecem não acreditar, observando-se, em seguida, duas perguntas que comportam insinuações, já que foram formuladas com certa carga de ironia, fato perceptível pelos risos que provoca nos entrevistadores:

L] | foi aprovado? ((risos))

L] | com média sete ou média cinco governador?

A estrutura dos enunciados e o modo como estes são formulados constituem aspectos do contexto em que os participantes estão envolvidos e que determinam a organização das ações subseqüentes. É assim que Fleury reorganiza suas ações, não responde, preferindo reclamar por relevância, numa formulação que poderia possibilitar um redirecionamento do tópico:

L.2 (...) até agora só falamos de de de dúvidas que surgem... a gente pode falar de realizações também...

mas o governador não consegue que o tópico tome outra direção, como se de verifica no transcorrer da entrevista.

É preciso ressaltar que há inúmeras formas de organização discursiva reveladoras de controle do discurso. Dentre elas, destacamos as perguntas, por se constituírem em verdadciras estratégias utilizadas na conversação que podem comportar finalidades específicas, possibilitando que os resultados obtidos scjam cumulativos. Se observarmos, no segmento indicado na entrevista sob análise, a insistência por parte de I 9 na formulação dirigida ao entrevistado, podemos detectar que a pergunta corresponde a uma das técnicas utilizadas pelo entrevistador, no caso, como forma de retomada de um tópico que lhe interessa, ao mesmo tempo que ameaça a face do interlocutor:

Esse mesmo fato pode ser verificadono segmento às linhas 168 e ss., em que se tratava de um "tema altamente polêmico", segundo a indicação do próprio entrevistador, L A, correspondente ao processo de aposentadoria do Covernador: 
FÁVERO, Leonor Lopes., el alii. As perguntas na organização das entrevistas.

L4 o senhor assinou um artigo no jornal... O Estado de São Paulo... no dia 9 de julho de $93 . .$. intitulado... "Revisão Indispensável"... o senhor cita:: tem seguinte trecho no seu artigo aspas... como terceira grande reforma... impöe-se dentro da revisão constitucional... temos a reforma previdenciária... c impõe-se uma ampla revisão... sem temor de abandonar temas Altamente polêmicos... como idade mínima para aposentadoria

I.2 exato

L4 o senhor mudou depois de opini:: opinião?

L2 não não mudei eu exerci um direito meu se é isso que o você que dizer... eu exerci um direito meu porque não mudaram a constituição...

Mais adiante, às linhas 586 e ss., outro entrevistador retoma o tópico por meio de uma pergunta:

L.5

(...) a informação que eu tenho é que o senhor não pretendia tomar essa medida houve uma mudança no seu/?

L.2 houve... houve uma mudança

I.5

I

L2 o:: o::de idéia?

o que fez o senhor mudar?

1,5 é

L2 eu achei que se eu fosse me aposentar depois de deixar o governo... ah:: poderia haver uma uma grita ainda maior... esperou sair do governo para se aposentar na calada da noite... eu fiz questão de fazer de uma forma absolutamente transparente todo mundo sabe que eu me aposentei... que eu tinha o direito... de me aposentar...

Os entrevistadores insistem na retomada do tópico "aposentadoria" que parece fragilizar o entrevistado junto à terceira parte. Fleury indicara que mudou de idéia em relação à aposentadoria e observamos que o fizera em benefício próprio; em seguida, afirmara que se aposentou porque tinha direito a agir assim e, no segmento a seguir (linhas 728 e ss.), finaliza respondendo a L 49 que precisa da aposentadoria para viver. As perguntas que retomam o tópico se colocam como ameaça à face do Covernador:

L9 o governador... o::: o:: na semana passada eu queria fazer uma pergunta ((tosse)) também ao senhor sobre essa questão ((tosse)) da aposentadoria 
L.2 pois não

L9 éh::: mas queria passar de passagem porque cu acho que essa outra questão a que... é mais... relevante pra população de São Paulo... mas não o senhor não tá sofrendo um desCAste eXAgeRAdo com essa questão da da da aposentadoria o senhor preClsa dessa aposentadoria?

l.2 preciso... eu preciso dela... cu vivo do meu salário

\section{CONCLUSĀO}

As análises permitem confirmar o fato de que, de acordo com os objetivos, os falantes organizam suas ações de modo a alcançar os fins a que se propuseram no início da interação e que as perguntas se configuram como elementos imprescindíveis na organização do texto de entrevistas, prestando-se a consolidar ou modificar as relações entre os interlocutores (entrevistado, entrevistador ou terceira parte), imprimindo um caráter vivo ao evento discursivo.

Constituem-se, assim, em estratégias que acumulam efeitos, já que o entrevistador, muitas vezes, formula um pedido de informação, de confirmação ou esclarecimento, por exemplo, mas ao mesmo tempo utiliza as perguntas para mudar ou redirecionar o tópico, além de aproveitar, se for o caso, para cxpor a face do outro participante. Vão, portanto, muito além do simples papel de conseguir informações, possibilitando que se mostrem as faces dos interlocutores, podendo revestir-se de uma carga irônica, dependendo do contexto em que sejam formuladas.

As perguntas permitem que se observe, inclusive, um jogo de poder, como ocorreu em nossas análises por parte dos entrevistadores que, ao interrogarem, revestiram suas perguntas de ironia, imprimindo um caráter de desvalorização da fala do entrevistado. Ao mesmo tempo em que ocorrem num determinado contexto, as perguntas permitem que ele seja cria- 
FÁVERO, Lconor lopes., el alii. As perguntas na organização das entrevistas.

do, recriado, imprimindo a este um aspecto que o distancia do campo da neutralidade.

ABSTRACT: This paper discusses questions as elements wich organize interviews, not only about turn, but yet in discourse topic relation, becoming interaction dynamic and reorganizing context.

KEVWORDS: interview, dialogic pair; context and relevance, discourse topic.

\section{BIBLIOGRAFIA}

AQUINO,Z.C.O. (1997) Conversação e conflito: um estudo das estratégias discursivas em interações polêmicas. 2 vols. Tese (Doutorado em Lingüística) FFLCH - Universidade de São Paulo.

DURANTI, A., GOODWIN, C.(ed.) (1992) Rethinking contexl - Language as an interactive phenomenon. Cambridge: Cambridge University Press.

FÁVERO, L., ANDRADE, M.L., AQUINO, Z. (1996) Perguntas e respostas como mecanismos de coesão e cocrência no texto falado. In: A.T.Castilho, M. Basílio (orgs.) Gramálica do Porluguês Falado. V. IV: Estudos descritivos. Campinas, SP: Editora da UNICAMP/FAPESP, p. 473-508.

GARRET, A.(1981) A entrevista, seus princípios e métodos. Rio de Janciro: Agir:

CAULMYN, M.M. (1991) La question dans tous ses états. I es cinq types de questions de l'explication conversationelle. In C.Kerbrat-Orecchioni (org.). La question. Lyon: Presses Universitaires de Lyon.p.295-322.

COFFMAN, E. (1981) Forms of lalk. Philadelphia: University of Pensylvania Press.

COODWIN, COODWIN, (1992) Assesment and construction of context. In: A. DURANTI, C. GOODWIN (ed.) Rethinking context - Language as an interactive phenomenon. Cambridge: Cambridge University Press. p.147-190.

KERBRAT-ORECCIIIONI, C. (org.) (1991) La question. Lyon: Presses Universitaires de Lyon.

LINDSTROM, L. (1992) Contxt contests: debatable truth statements in Tanna (Vanuatu). In: $\Lambda$. DURANTI, C. COODWIN (ed.) Rethinking context - Language as an interactive phenomenon. Cambridge: Cambridge University Press. P.101-124. 
Revista da ANPOLL, n" 4, p. 121-135, jan./jun. 1998

MARCUSCIII, L.A. (1986) Análise da Conversação. São Paulo: Ática.

MEDINA, Cremilda A. (1990) Entrevista - o diálogo possível. 2 ed. São Paulo: Ática.

PRETI, D. c URBANO,H.(orgs.) (1988) A linguagem falada culta na cidade de São Paulo. vol.III - Entrevistas (Diálogos entre informante e documentador). Projeto NURC/SP. São Paulo: T.A.Quciroz /FAPESP.

SACKS, II., SCIECLOFF, E., JEFFERSON, C. (1974) $\Lambda$ simplest systematics for the organization of turn-taking in conversation. In: Language, 50. Baltimore: Iinguistic Society of America.

URBANO, H. (1988) Apresentação. In: D. Pretti, II. Urbano (orgs.) A linguagem falada culta na cidade de São Paulo. v.III - Entrevistas (Diálogos entre informante e documentador). Projeto NURC/SP. São Paulo: T.A.Queiroz /FAPESP. 